\title{
Is All-Weather Strategy Underperformed During COVID-19? An Evidence from US's Etfs Market
}

\author{
Feitong Shan ${ }^{1, *}$ \\ ${ }^{1}$ School of International Business, Shandong Technology and Business University, Yantai 264003, China
${ }^{*}$ Corresponding author. Email: 2018220122@sdtbu.edu.com
}

\begin{abstract}
In 2008, Bridgewater's all-weather strategy overperformed the market. Dario, founder of Bridgewater, and his team pioneered the all-weather strategy in 1996, and it's been a huge success in practice. However, according to the daily report of bridgewater associate on March 18th 2020, the all-weather portfolio suffered great losses. The all-weather strategy is based on the idea of risk parity. This paper aims to discuss the possible reason for the massive losses that all-weather funds have suffered during pandemic. The conclusion is that the all-weather performed not ideally in 2020 due to its intrinsic characteristics - risk parity and the worsen economic environment resulted from the breakout of COVID-19. The popularity of this tragedy as well as the widely used leverage in all-weather strategy also aggravated the already severe situation.
\end{abstract}

Keywords: All-weather portfolio, Risk parity strategy, Capital market, financial crisis

\section{INTRODUCTION}

Markowitz [1] found the mean-variance theory, which is the foundation of modern portfolio theory. Markowitz regarded the price change of the portfolio as a random variable and used its mean to measure returns and its variance to measure risks. Taking the weights of all kinds of securities in the portfolio as a variable, the problem in solving the minimum risk of the portfolio is reduced to the quadratic programming problem under linear constraints. Sharpe [2] developed a capital asset pricing model, abbreviated as CAPM. He uses a sharp ratio to select a portfolio. The capital asset pricing model clarified the relationship between risk and return, and the non-systematic risk is dispersed through the portfolio.

Since the 1990s, experts and scholars began to pay attention to the risk management of assets. In 1996, Dalio [3], the founder of Bridgewater Associates, launched an all-weather strategic fund by keeping the risks of portfolio completely consistent in different economic environments to achieve a balanced risk allocation, reflecting the idea of risk parity. In 2008, Bridgewater made a name because the all-weather fund managed by Ray Dalio lost only $-3.93 \%$ versus the S\&P 500 's nearly $-40 \%$ loss. However, on March 18th 2020, Bridgewater's all-weather fund $(12 \%)$ was down about $14 \%$, which was slightly better than S\&P's $-18 \%$ loss.
The general performance of all-weather portfolios and risk parity funds could not compare to what they achieved in 2008. It is vital to find the reason behind the fall of the legend.

This paper first used the Markowitz optimization to find the weights that met the need of risk parity and constructed the risk parity fund to compare its performance with the simple version of the all-weather fund provided by Dalio. The all-weather portfolio slightly overperformed the risk parity portfolio in the analysis, but none suffered the degree of losses as Bridgewater's daily report suggested. Second I applied leverage to the all-weather portfolio to test whether leverage has a connection with the underperformance of all-weather strategy. Third I analyzed the correlation of each asset class in 2020. The result was that almost every asset showed more correlation during the pandemic, and the loss of effectiveness in all-weather strategy might be derived from that.

\section{METHOD}

\subsection{Asset allocation models}

This part first introduced a method of asset allocation and demonstrated the optimisation process to find the weight of each asset in a portfolio. It also introduced a simple-version of the all-weather strategy 
given by Dalio. So we could compare these two portfolios in the following chapter.

\subsubsection{Risk parity model}

According to the bridgewater associate, the risk parity model is based on the idea of balancing one's risk exposures across multiple sources of return to achieve the most consistent performance across all future environments. The simplest weighting rule for risk parity is that the weight of assets is inversely proportional to the standard deviation of return on assets. Since the above method resulted in a large proportion of low-yielding assets, the expected return can be achieved [4] by increasing leverage.

We assume $w_{i}$ is the weight of asset $\mathrm{i}$ and $\sigma_{i j}$ is the covariance of asset $\mathrm{j}$ and asset $\mathrm{i}$.

The standard deviation can be defined as

$$
\sigma_{P}=\sqrt{\sum_{\mathrm{i}=1}^{\mathrm{n}} \sum_{\mathrm{j}=1}^{\mathrm{n}} \mathrm{w}_{\mathrm{i}} \mathrm{w}_{\mathrm{j}} \sigma_{\mathrm{ij}}}
$$

Demand $\sigma_{\mathrm{P}}$ on the partial derivatives, and the result is the marginal risk contribution of asset $i$.

$$
\mathrm{MRC}_{\mathrm{i}}=\frac{\partial \sigma_{\mathrm{P}}}{\partial \mathrm{w}_{\mathrm{i}}}=\sum_{\mathrm{j}=1}^{\mathrm{n}} \mathrm{w}_{\mathrm{j}} \sigma_{\mathrm{ij}}
$$

The total risk contribution of asset $i$ to the portfolio is

$$
\mathrm{TRC}_{\mathrm{i}}=\mathrm{w}_{\mathrm{i}} \frac{\partial \sigma_{\mathrm{P}}}{\partial \mathrm{w}_{\mathrm{i}}}=\sum_{\mathrm{j}=1}^{\mathrm{n}} \mathrm{w}_{\mathrm{i}} \mathrm{w}_{\mathrm{j}} \sigma_{\mathrm{ij}}
$$

Since risk parity demand each asset have the same risk contribution, so

$$
\mathrm{TRC}_{\mathrm{i}}=\mathrm{TRC}_{\mathrm{j}}=\mathrm{w}_{\mathrm{i}} \frac{\partial \sigma_{\mathrm{P}}}{\partial \mathrm{w}_{\mathrm{i}}}=\mathrm{w}_{\mathrm{j}} \frac{\partial \sigma_{\mathrm{P}}}{\partial \mathrm{w}_{\mathrm{j}}} \text {, for all } \mathrm{i} \neq \mathrm{j}
$$

$$
\sum_{\mathrm{i}=1}^{\mathrm{n}} \sum_{\mathrm{j}=1}^{\mathrm{n}}\left(\mathrm{TRC}_{\mathrm{i}}-\mathrm{TRC}_{\mathrm{j}}\right)^{2}=0
$$

This can transformed the process of solving the optimal weights

$$
\min \sum_{\mathrm{i}=1}^{\mathrm{n}} \sum_{\mathrm{j}=1}^{\mathrm{n}}\left(\mathrm{TRC}_{\mathrm{i}}-\mathrm{TRC}_{\mathrm{j}}\right)^{2}
$$

Subject to $\sum_{i=1}^{n} w_{i}=1 \quad$ and $\quad 0 \leq \mathrm{w}_{\mathrm{i}} \leq 1, \mathrm{i}=$ $1,2, \ldots, \mathrm{n}$

\subsubsection{All-weather portfolio}

The all-weather strategy is designed to construct a portfolio that can adapt to various economic environments over a long period while achieving average market returns with minimal risk and does not require any active management.

Several concepts are the principle behind the allweather strategy. First, the All-weather strategy does not rely on the return generated by individuals but seeks Beta, which represents the risk premium derived from market risk. Second, the approach that all-weather strategy minimize risk uses the upward economic cycle to hedge against the downward economic cycle. The diversification is not among asset allocation but on the macroeconomic state. As illustrated in table 1, the allweather strategy divides the macroeconomic environment into four states, rising growth, falling growth, rising inflation and falling inflation. Several assets perform better than others in a certain state. Third, risk parity is in the allocation. In every economic state, construct a portfolio with advantageous assets and make risk contribution of each asset equals other assets within the portfolio. Construct a bigger portfolio with the four portfolios based on different economic states and apply the same risk parity approach. Forth, apply leverage to debt instruments to seek higher returns [5]. By leveraging the expected return of bonds, it will be in line with the return of equities. After that, calculate the weight that makes equities and bonds contribute the same risk to the portfolio.

Table 1. Macro environment matrix

\begin{tabular}{lcc}
\hline & Growth & Inflation \\
\hline $\begin{array}{l}\text { Risi } \\
\text { ng }\end{array}$ & $25 \%$ of Risk & $25 \%$ of Risk \\
& Equities & $\begin{array}{c}\text { Inflation-linked } \\
\text { bonds }\end{array}$ \\
& Corporate bond & Commodities \\
& Commodities & EM debt spreads \\
& EM debt spreads & \\
Fall & $25 \%$ of Risk & $25 \%$ of Risk \\
ing & Nominal bonds & Equities \\
& $\begin{array}{l}\text { Inflation-linked } \\
\text { bonds }\end{array}$ & Nominal bond \\
\hline
\end{tabular}

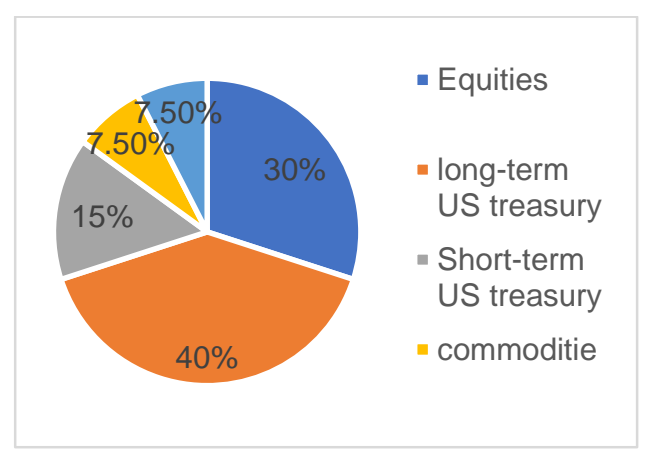

Figure 1. The weight of asset allocation of the allweather portfolio

Figure 1 shows the asset allocation results provided by Ray Dalio. According to him, this is the simple 
version of the all-weather strategy Bridgewater currently used.

\subsection{Choice of data}

This section introduced the data for the construction of an all-weather portfolio. The choice of data refers to the version of Ray Dalio's all-weather model. To construct the portfolio, five ETFs are selected to represent each asset class:

Table 2. The selection of ETFs for leveraged and nonleveraged portfolio

\begin{tabular}{|c|c|c|c|c|c|}
\hline $\begin{array}{l}\text { Asset } \\
\text { classes }\end{array}$ & $\begin{array}{l}\text { equitie } \\
\mathrm{S}\end{array}$ & $\begin{array}{l}\text { Long } \\
\text { term } \\
\text { US } \\
\text { treasur } \\
\text { y }\end{array}$ & $\begin{array}{l}\text { Short } \\
\text { term } \\
\text { US } \\
\text { treasur } \\
\text { y }\end{array}$ & $\begin{array}{l}\text { commodi } \\
\text { ties }\end{array}$ & gold \\
\hline $\begin{array}{l}\text { Non- } \\
\text { leverag } \\
\text { ed ETF }\end{array}$ & $\begin{array}{l}\text { VTI - } \\
\text { Vangu } \\
\text { ard } 500 \\
\text { Index } \\
\text { Investo } \\
\text { r }\end{array}$ & $\begin{array}{l}\text { TLT - } \\
\text { iShares } \\
20+ \\
\text { Year } \\
\text { Treasu } \\
\text { ry } \\
\text { Bond } \\
\text { ETF }\end{array}$ & $\begin{array}{l}\text { IEF - } \\
\text { iShares } \\
7-10 \\
\text { Year } \\
\text { Treasu } \\
\text { ry } \\
\text { Bond } \\
\text { ETF }\end{array}$ & $\begin{array}{l}\text { DBC - } \\
\text { Invesco } \\
\text { DB } \\
\text { Commod } \\
\text { ity } \\
\text { Tracking }\end{array}$ & $\begin{array}{l}\text { GLD - } \\
\text { SPDR } \\
\text { Gold } \\
\text { Shares }\end{array}$ \\
\hline $\begin{array}{l}\text { Levera } \\
\text { ged } \\
\text { ETF }\end{array}$ & $\begin{array}{l}\text { SSO - } \\
\text { ProSha } \\
\text { res } \\
\text { Ultra } \\
\text { S\&P50 } \\
0\end{array}$ & $\begin{array}{l}\text { UBT - } \\
\text { ProSha } \\
\text { res } \\
\text { Ultra } \\
20+ \\
\text { Year } \\
\text { Treasu } \\
\text { ry }\end{array}$ & $\begin{array}{l}\text { UST - } \\
\text { ProSha } \\
\text { res } \\
\text { Ultra } \\
7-10 \\
\text { Year } \\
\text { Treasu } \\
\text { ry }\end{array}$ & $\begin{array}{l}\text { DIG - } \\
\text { ProShare } \\
\text { s Ultra } \\
\text { Oil\&Gas }\end{array}$ & $\begin{array}{l}\text { UGL - } \\
\text { ProSha } \\
\text { res } \\
\text { Ultra } \\
\text { Gold }\end{array}$ \\
\hline
\end{tabular}

The data of ETFs that were used to construct a nonleveraged portfolio can be found from 2007 to 2021. However, since UST was founded in 2010 , the period for the leveraged portfolio was constrained by it.

All the data comes from Yahoo finance.

\section{ANALYSIS OF THE LEVERAGE IN THE ALL-WEATHER PORTFOLIO}

\subsection{Non-leveraged all-weather portfolio}

We first examine the performance of the all-weather strategy and compare it to S\&P 500. The time window of the following data is from Jan 2007 to Jul 2021.

Table 3. The performance of the all-weather strategy and S\&P 500

\begin{tabular}{ccccc}
\hline Portfolio & CAGR & $\begin{array}{c}\text { Standard } \\
\text { deviation }\end{array}$ & $\begin{array}{c}\text { Max. } \\
\text { Drawdown }\end{array}$ & $\begin{array}{c}\text { Sharpe } \\
\text { ratio }\end{array}$ \\
\hline $\begin{array}{c}\text { All- } \\
\text { weather }\end{array}$ & $8.08 \%$ & $7.39 \%$ & $-11.98 \%$ & 0.98 \\
\hline
\end{tabular}

$\begin{array}{lllll}\text { portfolio } & & & & \\ \text { S\&P 500 } & 10.19 \% & 15.36 \% & -50.79 \% & 0.66\end{array}$

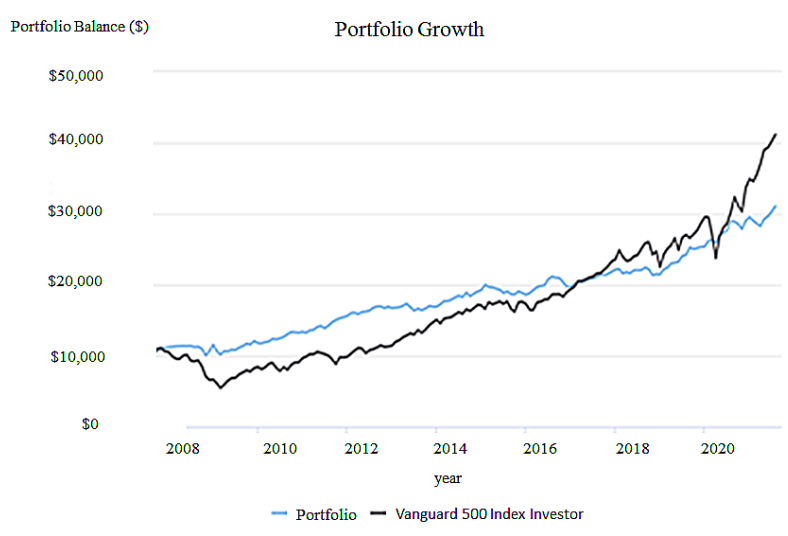

Figure 2. The growth of all-weather portfolio with $S \& P$ 500 as the benchmark

From table 3 and figure 2, we can find that the allweather portfolio had less volatility than that of S\&P and a higher risk-adjusted return, represented by the Sharpe ratio. The maximum drawdown of the allweather portfolio is also much lower than that of S\&P. This shows the all-weather portfolio can hedge against risk during different economic situations. However, in 2008 all-weather portfolio made a significantly high return. In 2020, the gap between the all-weather portfolio and S\&P has narrowed, and the return of the all-weather portfolio is not attractive.

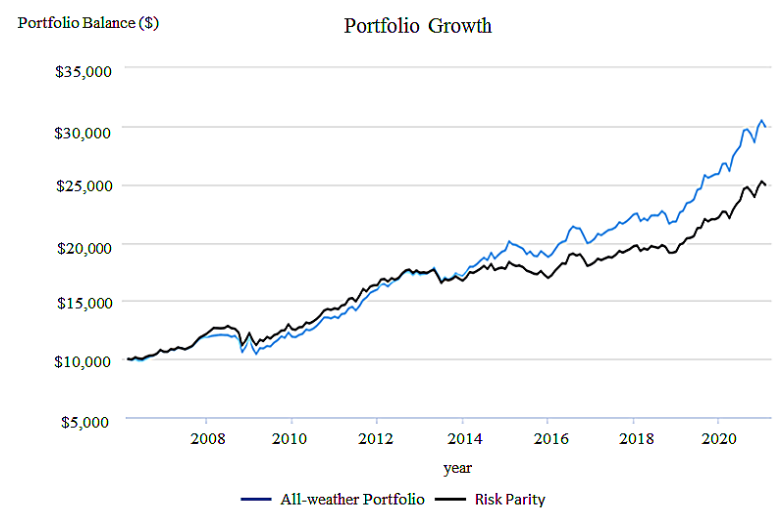

Figure 3. The portfolio growth of all-weather portfolio and risk parity portfolio

The comparison of risk parity and all-weather strategy in figure 3 shows that the volatility of an allweather portfolio whose calculation is based on Dalio's disclosure is lower than that of a risk parity portfolio, which is strictly calculated through the risk parity model. The reason for the difference might be the higher leverage that Dalio primarily introduced in his portfolio. 
Under the model given by Dalio in figure 1, bond takes a large proportion in the portfolio [7]. Because the volatility of bonds is much lower than that of equity, if the leverage of bond cannot be added efficiently, the majority of the fund of the overall portfolio will be invested in the bond, which will lead to the problem of low volatility of the overall portfolio and the expected return cannot reach the target of investors. To acquire a higher return that is at least close to the S\&P 500, adding leverage falls within the simulation's scope.

\subsection{Apply leverage in the all-weather strategy}

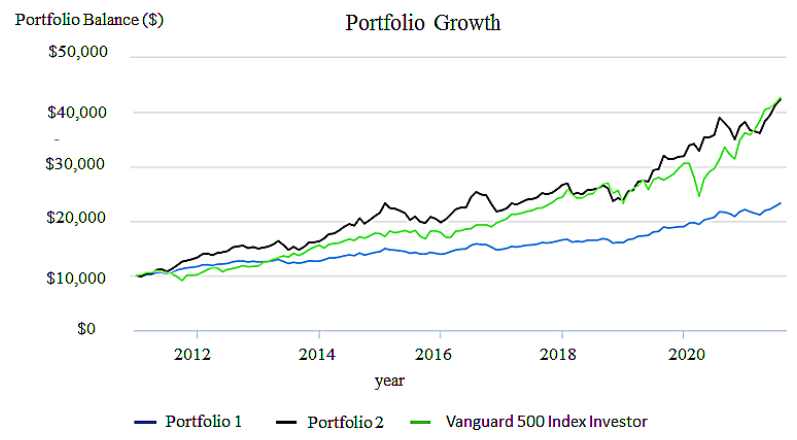

Figure 4. The growth of non-leveraged all-weather portfolio (portfolio 1) and leveraged all-weather portfolio (portfolio 2) with S\&P 500 as the benchmark from 2007 to 2021

Table 4. Portfolio Performance (Jan 2020 - Jan 2021)

\begin{tabular}{|c|c|c|c|}
\hline & $\begin{array}{l}\text { Non- } \\
\text { leveraged } \\
\text { Portfolio }\end{array}$ & $\begin{array}{l}\text { Leveraged } \\
\text { Portfolio }\end{array}$ & $\begin{array}{l}\text { Vanguard } \\
500 \text { Index } \\
\text { Investor }\end{array}$ \\
\hline CAGR & $13.18 \%$ & $13.71 \%$ & $15.63 \%$ \\
\hline $\begin{array}{l}\text { Standard } \\
\text { deviation }\end{array}$ & $8.44 \%$ & $16.67 \%$ & $24.99 \%$ \\
\hline $\begin{array}{l}\text { Worst month } \\
\text { (March) }\end{array}$ & $-1.71 \%$ & $-3.97 \%$ & $-1.02 \%$ \\
\hline \multicolumn{4}{|c|}{$\begin{array}{l}\text { From figure } 4 \text {, we can find that the line of the } \\
\text { leveraged all-weather portfolio is less smooth than that } \\
\text { of the non-leveraged one. The volatility of the leveraged } \\
\text { portfolio is unsurprisingly higher than that of the non- } \\
\text { leveraged portfolio. With the rising leverage, the loss } \\
\text { during unprivileged circumstances increased from - } \\
1.71 \% \text { to }-3.97 \% \text { (table } 4 \text { ). So we regard the }-14 \% \text { losses } \\
\text { of Bridgewater's all-weather fund during } 18 \text { th March } \\
2020 \text { as the dependence of financing, an intrinsic } \\
\text { characteristic of leveraging, which is shrinking during } \\
\text { extreme economic environments. }\end{array}$} \\
\hline
\end{tabular}

\section{DISCUSSION}

The application of leverage in all-weather strategy during pandemic deteriorated the performance and the already worsening environment. Due to the breakout of Coronavirus, the whole market was facing uncertainty, which led to a sharp increase in volatility. During the crisis, banks withdrew liquidity to protect themselves from more disadvantageous situations [6]. This meant the reduction of leverage was inevitable. Since models based on risk-parity strategies required consistent risk metrics, every asset had to be slashed and sold.

Apart from the leverage added in the all-weather portfolio, the requirement of risk parity, the all-weather portfolio's core principle, also made the performance of the all-weather portfolio below expectation. The lockdown caused almost every industry to shut down, and the cease of production led to the demand for oil and other commodities to decrease [8]. The risk exposure on commodities resulted in the cutdown of commodity assets, and the position of other assets must decrease to achieve "risk parity".

Moreover, Germany, the United Kingdom, South Korea, Italy announced a partial ban [9] on short selling. Some of the strategies cannot be used. For example, the ETFs in these countries would not be used for diversification. According to the model, the position of other assets needs to be slashed.

Why all-weather strategy survived the financial crisis in 2008 but did not perform equivalent quality in 2020? Apart from the two factors derived from the model itself, there is one reason worth discussing.

All-weather portfolios allocated various assets with low correlations among the globe, and it should fulfil its duty of reducing volatility. Since 2008 all-weather strategy has been widely used among hedge funds. As time went by, the amount of funds were large enough to influence the market. The correlation of these formally low-correlated assets has increased [10] due to the large number of funds doing the same transaction simultaneously. Take the correlation between GLD and VTI. For example, the correlation reached the highest point in 2020. The heavy use of the all-weather strategy created a correlation between gold and stock, and this caused the primarily safe heaven asset-gold to lose its effectiveness. 


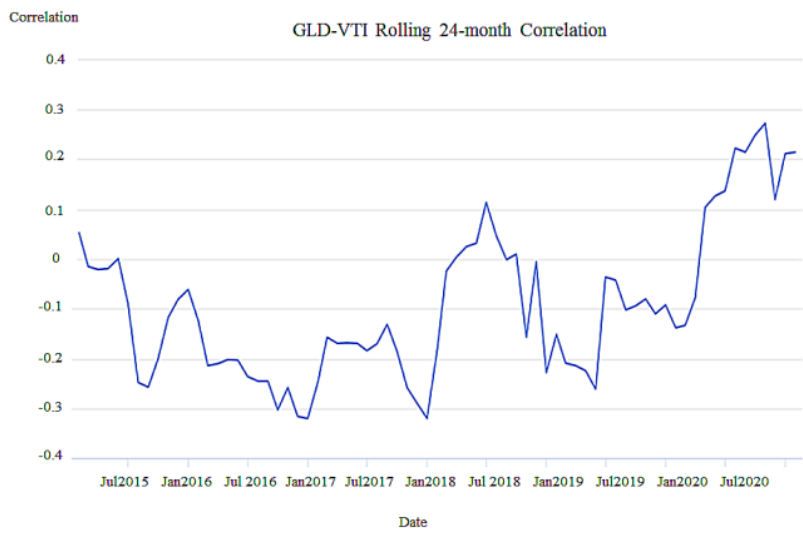

Figure 5. The rolling 24-month correlation between GLD and VTI

\section{CONCLUSION}

From the analysis above, we found that the risk parity strategy meets its goal of managing risk over a long period, but the return could not beat S\&P 500 in recent years. Then the comparison of risk parity portfolio, which strictly meets risk contribution equality, and a simple version of Bridgewater's all-weather portfolio developed by Dalio showed that the risk parity strategy was also not competitive with the S\&P 500. Therefore, we used leveraged all-weather portfolio to make a new simulation, and the volatility is twice that of the non-leveraged risk parity approach. So the application of leverage is a tradeoff. As the times of leverage increase, the more loss it suffers during the crisis and the more it reaches the level of actual loss in Bridgewater's fund.

We explained the specific condition resulted from the pandemic and its influence. In the end, we proposed the idea that the all-weather strategy itself also created an unfavorable effect.

The final part of the discussion part only proposed an explanation of a reason for the great loss that the allweather fund suffered, but no more data and statistical analysis.

\section{REFERENCES}

[1] Michaud, R. O. (1989). The Markowitz optimization enigma: Is 'optimized' optimal?. Financial analysts journal, 45(1), 31-42.

[2] Sharpe, W. F. (1994). The sharpe ratio. Journal of portfolio management, 21(1), 49-58.

[3] Keller, W. J. (2020). Lazy Momentum with Growth-Trend timing: Resilient Asset Allocation (RAA). Available at SSRN 3752294.

[4] Chaves, D., Hsu, J., Li, F., \& Shakernia, O. (2011). Risk parity portfolio vs. other asset allocation heuristic portfolios. The Journal of Investing, 20(1), 108-118.

[5] Lohre, H., Opfer, H., \& Orszag, G. (2014). Diversifying risk parity. Journal of Risk, 16(5), 5379.

[6] Asness, C. S., Frazzini, A., \& Pedersen, L. H. (2012). Leverage aversion and risk parity. Financial Analysts Journal, 68(1), 47-59.

[7] Anderson, R. M., Bianchi, S. W., \& Goldberg, L. R. (2012). Will my risk parity strategy outperform? Financial Analysts Journal, 68(6), 75-93.

[8] Louraoui, Y. (2021). The All-Weather Portfolio Approach: Analysis of the Strategy on a 10-Year Timeframe, Insights and Investment Lessons. Insights and Investment Lessons (April 1, 2021).

[9] Siciliano, G., \& Ventoruzzo, M. (2020). Banning Cassandra from the Market? An Empirical Analysis of Short-Selling Bans during the Covid19 Crisis. European Company and Financial Law Review, 17(3-4), 386-418.

[10] Syahri, A., \& Robiyanto, R. (2020). The correlation of gold, exchange rate, and stock market on Covid-19 pandemic period. Jurnal Keuangan dan Perbankan, 24(3), 350-362. 